\title{
Clinical characteristics and time trends of hospitalized methadone exposures in the United States based on the Toxicology Investigators Consortium (ToxIC) case registry: 2010-2017
}

Omid Mehrpour ${ }^{1,2^{*}}$ (D) Christopher Hoyte ${ }^{1,3}$, Alireza Amirabadizadeh ${ }^{2,4}$, Jeffrey Brent ${ }^{5}$ and On behalf of the Toxicology Investigators Consortium (ToxIC)

\begin{abstract}
Background: Methadone is well known for its long duration of action and propensity for mortality after an overdose. The present research was aimed at evaluating the clinical manifestations and time trends of methadone exposure in patients in US hospitals.

Methods: We queried the American College of Medical Toxicology's Toxicology Investigators Consortium case registry for all cases of methadone exposure between January 1, 2010, and December 31, 2017. The collected information included demographic features, clinical presentations, therapeutic interventions, poisoning type (acute, chronic, or acute on chronic), and the reason(s) for exposure. Descriptive data and relative frequencies were used to investigate the participants' characteristics.

Our data analysis was performed using SPSS version 19 and Prism software. The trends and clinical manifestations of methadone poisoning over the time period of the study were specifically investigated.

Results: Nine hundred and seventy-three patients who met our inclusion criteria, with a mean age of $41.9 \pm 16.6$ years (range: 11 months-78 years) were analyzed. Five hundred eighty-two (60.2\%) were male. The highest rate of methadone poisoning was observed in 2013. There was an increasing rate of methadone exposures in 2010-2013, followed by a decline in 2014-2017. The most common clinical manifestations in methadone-poisoned patients were coma (48.6\%) and respiratory depression (33.6\%). The in-hospital mortality rate of methadone poisoning was $1.4 \%$.
\end{abstract}

Conclusion: ToxIC Registry data showed that inpatient methadone exposures enhanced from 2010 to 2013, after which a reduction occurred in the years 2014 to 2017.

Keywords: Methadone, Poisoning, Trend, Toxicology investigators consortium (ToxlC), United States

\footnotetext{
* Correspondence: Omid.mehrpour@yahoo.com.au

${ }^{1}$ Rocky Mountain Poison and Drug Center, Denver Health and Hospital

Authority, 1391 Speer Blvd, 777 Bannock St. MC 0180, Denver, CO 80204,

USA

${ }^{2}$ Medical Toxicology and Drug Abuse Research Center (MTDRC), Birjand

University of of Medical Sciences, Birjand, Iran

Full list of author information is available at the end of the article
}

(c) The Author(s). 2020 Open Access This article is licensed under a Creative Commons Attribution 4.0 International License, which permits use, sharing, adaptation, distribution and reproduction in any medium or format, as long as you give appropriate credit to the original author(s) and the source, provide a link to the Creative Commons licence, and indicate if changes were made. The images or other third party material in this article are included in the article's Creative Commons. licence, unless indicated otherwise in a credit line to the material. If material is not included in the article's Creative Commons licence and your intended use is not permitted by statutory regulation or exceeds the permitted use, you will need to obtain permission directly from the copyright holder. To view a copy of this licence, visit http://creativecommons.org/licenses/by/4.0/. The Creative Commons Public Domain Dedication waiver (http://creativecommons.org/publicdomain/zero/1.0/) applies to the data made available in this article, unless otherwise stated in a credit line to the data. 


\section{Background}

Methadone was developed in Germany in 1937 and introduced to the United States (US) in 1947 [1]. It is a prescription opioid and is currently one of the primary options for the medication-assisted therapy of opioid use disorder [2] and for alleviating chronic pain. However, it has a high abuse potential [3]. Methadone has the highest rate of mortality in overdose of prescribed opioid analgesics in the US [4] and is an important cause of opioid-related deaths in many other countries [5]. In 2011, in the US alone, approximately 180,000 patients were reported to be on methadone maintenance therapy [6]. Another survey in the US reported that the number of individuals receiving methadone increased from about 227,000 in 2003 to over 350,000 in 2015 [7].

Along with the increased use of methadone comes an increased risk of side effects or adverse reactions related to overdose, such as rhabdomyolysis, sedation, sweating, respiratory depression, dizziness, nausea, dysrhythmias, vomiting, itching, constipation, orthostatic hypotension, prolongation of the QT interval, and death [1]. Despite the large numbers of potentially serious sequelae of methadone use, few studies have evaluated trends in methadone toxicity in the US. Therefore, we aimed to evaluate the trends and patient-related factors associated with cases of methadone exposure seen in US hospitals by utilizing a well-established prospective clinical database.

\section{Methods}

We queried the Toxicology Investigators Consortium (ToxIC) Case Registry for all cases of methadone poisoning recorded between Jan 1, 2010, and December 31, 2017. The ToxIC Registry prospectively records cases cared for by participating medical toxicologists. It was designed to collect data by medical toxicologists and thus is felt to represent toxicologically accurate information. Members of the Consortium consist of all medical toxicologists from participating sites. Although this has varied from year to year, there are currently 49 sites participating in ToxIC, comprising the majority of US medical toxicology training programs and practices.

Patient data is entered into the ToxIC Registry via an online interface on which information is recorded on the substances involved, patient demographics, presenting signs and symptoms, toxidromes, treatments administered, and outcomes. The ToxIC Registry has been described in detail previously [8-10].

For the current study, we queried the ToxIC Registry for the following patient variables: gender, age, race, data pertaining to the cause of the exposure, agents involved, route of exposure (e.g. oral, parenteral), clinical manifestations, including toxidromes, abnormalities of vital signs, renal, cardiovascular, nervous system, gastrointestinal, metabolic, pulmonary, hematologic, muscle, and dermatologic effects; therapeutic interventions, including antidotes, medication treatment, decontamination, elimination techniques, and pharmacologic and nonpharmacologic support. Intentional methadone exposure was defined as any ingestion taken for therapeutic purposes, self-harm, or misuse/abuse.

Our inclusion criterion was any inpatient case in the ToxIC Registry where methadone was an implicated causal agent. Patients were excluded if the data related to age, sex, or cause of toxicological consultation was missing, if they were outpatients, or if they were seen for methadone withdrawal. Accidental ingestions, and those due to pediatric exploratory behavior, were classified as unintentional. All other cases were classified as intentional exposures. The analyses included all patients of any age meeting inclusion criteria who were registered during the study period.

The ToxIC project took place after review by the Western IRB and individual IRBs of ToxIC sites. All data in the ToxIC Registry is patient-deidentified and collected during routine clinical care. It does not involve any patient interventions.

\section{Statistical and analytical methods}

Descriptive statistics and relative frequencies plus graphical techniques were applied for investigating the patients' features. Data analysis was performed using SPSS version 19 and Prism software. Descriptive data, including frequency, percentage, mean, and standard deviation, were extracted and analyzed. Variables are reported as mean or median \pm standard deviations.

Using the Chi-square test, we investigated the frequency distribution of clinical manifestations (coma, respiratory depression, seizure, etc.) in single- and coexposure cases. Also, using this test, we examined and compared the frequency distribution of administered treatment patients with single- and co-exposures. For comparing the mean methadone dose consumed, after investigating the normality using the KolmogorovSmirnov test through the Mann-Whitney nonparametric test, we compared the methadone doses, QTc, and the effect rates in patients with single- or co-exposure to methadone. Also, the frequency distribution of clinical effects was reported based chronicity of use in all methadone patients.

Distribution of the total number of intentional and unintentional methadone poisoning cases reported to the ToxIC Registry 2010-2017 was assessed by the Chisquare test. $P$ values of smaller than 0.05 were regarded as significant, although data were presented without regard to formal statistical significance. 


\section{Results}

Nine hundred and seventy-three patients who met our inclusion criteria, with a mean age of $41.9 \pm 16.6$ years (range: 11 months-78 years), and a median age of 45.0 years were analyzed. Seven cases were excluded based on our exclusion criteria (6 were outpatients, and one patient had missing data). Eight hundred and thirty-one (86.0\%) patients were 19-65 years old, and $28(2.9 \%)$ were under the age of 2 years. Five hundred eighty-two (60.2\%) were male.

Three hundred and fifty-four cases (36.4\%) had methadone-only exposures, and 619 (63.6\%) had had coingestants (Table 2). The mean dose of methadone in all cases was $111 \pm 122 \mathrm{mg}(\mathrm{mg})$ (range: $3-800)$, with a median dose of $90 \mathrm{mg}$. In the methadone-only group, the mean methadone dose was $114 \pm 129$, with a median of $95 \mathrm{mg}$. For the group with co-ingestants, the mean methadone dose was $104 \pm 124$, with a median of $80 \mathrm{mg}$. The mean methadone dose in patients who received naloxone was $112 \pm 108$, with a median of $91 \mathrm{mg}$. In patients who did not receive naloxone, the mean methadone dose was $110 \pm 137$, with a median of $90 \mathrm{mg}$. The Mann-Whitney test did not show any significant difference in the methadone dose between groups that did or did not receive naloxone $(p=0.18)$.

The route of exposure was known in 437 (44.9\%) patients. Of these, $420(44.8 \%)$ patients consumed methadone orally, and 17 (1.8\%) used a parenteral route. The chronicity of exposure, known in 607 patients, was acute in $411(67.7 \%)$ patients, acute on chronic in 136 (14.5\%), and chronic in $60(6.4 \%)$ patients.

Six hundred and fifty-two (67.6\%) patients had been referred to the medical toxicology service by the emergency department, 120 (12.5\%) by the admitting service, $86(8.9 \%)$ by another hospital service, and 66 (6.8\%) were transferred from outside hospitals (Table 1). The inhospital mortality rate of methadone poisoning was $1.4 \%$ (14 patients).

Seven hundred and sixty-eight (79.5\%) patients had intentional methadone exposures. Of these, 51 (6.6\%), $209(27.3 \%)$, and $508(66.1 \%)$ were due to avoidance of withdrawal, drug abuse, and attempts at self-harm,

Table 1 Frequency of sources of referral to medical toxicology services and demographic information

\begin{tabular}{|c|c|c|}
\hline Variable & Frequency /mean & Percent /SD \\
\hline Age (year) & 41.9 & 16.6 \\
\hline Dose (milligram) & 111.34 & 121.78 \\
\hline \multicolumn{3}{|l|}{ Source of referral } \\
\hline Emergency department (ED) & 652 & 67.5 \\
\hline Admitting Service & 120 & 12.4 \\
\hline Outside Hospital Transfer & 66 & 6.8 \\
\hline Poison center & 12 & 1.2 \\
\hline Request from another hospital service & 86 & 8.9 \\
\hline PCP or other Outpatient Treating MD & 14 & 1.4 \\
\hline Self-Referral & 1 & 0.1 \\
\hline Unknown & 15 & 1.5 \\
\hline \multicolumn{3}{|l|}{ Gender } \\
\hline Male & 584 & 60.0 \\
\hline Female & 389 & 40.0 \\
\hline \multicolumn{3}{|c|}{ Role of medical toxicologist and location of toxicology consultation } \\
\hline Attending (Inpatient) & 179 & 19.9 \\
\hline Consult (ED/Inpatient) & 757 & 80.1 \\
\hline \multicolumn{3}{|l|}{ Chronicity of exposure } \\
\hline Acute & 411 & 67.7 \\
\hline Acute on chronic & 136 & 14.5 \\
\hline Chronic & 60 & 6.4 \\
\hline \multicolumn{3}{|l|}{ Reason for methadone use } \\
\hline Withdrawal management & 51 & 5.2 \\
\hline Abuse & 209 & 21.4 \\
\hline Attempt at self-harm & 508 & 52.2 \\
\hline
\end{tabular}


respectively. As shown in Fig. 1, the highest rate of methadone poisoning was observed in 2013. There was an increasing rate of methadone exposures in 20102013, followed by a decline in 2014-2017. The highest number of intentional methadone poisoning cases was clearly increasing in 2010 and peaked in 2013-2014 with 137 and 136 cases, respectively. After 2014, there was a decline. The highest frequency of unintentional methadone poisoning was reported in 2011 (44 patients).

Chi-square testing comparing the different years during our study period indicated that the causes of methadone toxicity significantly varied with time $(\mathrm{X} 2=295.81$, $p<0.001)$. The highest percent of methadone cases reported to the ToxIC Registry relative to the overall number of cases reported to the Registry for each year was obtained in 2013 (n: 169 [17.5\% of all methadone cases reported]), and the lowest rate was in 2015 (n: 77 [7.9\%] [Fig. 2]). As is evident in Fig. 2, the frequency distribution of methadone poisoning cases in 2015 had a significant difference from the years 2011, 2012, 2013, 2014 $(p<0.001)$. The frequency distribution of methadone poisoning cases in 2017 had a significant difference from the years of 2011, 2012, 2013, $2014 \quad(p<0.001)$. Frequency distribution of methadone poisoning cases in 2010 , as well as 2016 , had a significant difference from the years of 2011, 2012, 2013, $2014(p<0.001)$. Tables 2 and 3 show the distribution of clinical effects and mean doses associated with various clinical manifestations for single-agent and co-ingestant exposure to methadone. In patients with co-ingestants, 88 (14.3\%) co-ingested sedative-hypnotics, 35 (3.6\%) oxycodone, 27 (2.8\%) heroin, and 353 (34.0\%) other substances.

The median (25th\%-75th\%) QTc in patients with methadone poisoning was 446.0 [430.0-480.0] milliseconds. The median (25th\%-75th\%) QTc in singleexposure and co-exposure methadone patients were 449.9 [438.0-462.9] and 435.2 [389.9-480.0] milliseconds, respectively $(p=0.28)$.
The most common clinical manifestations in methadone poisoned patients were coma $(48.6 \%)$ and respiratory depression (33.6\%) (Table 2), occurring at mean doses of 96.2 [56.8-125.0] and 37.5 [29.7-50.0] mg, respectively. Two percent of patients experienced seizures. The median dose of methadone in patients with seizures who ingested methadone alone was 138.2 [96.5-165.1] $\mathrm{mg}$, similar to the dose of methadone in patients with seizures in the co-ingestion group, which was 136.9 [103.6-172.3] mg (Table 3). The median (25th\%-75th \%) QTc in patients with and without seizure was 453.0 [438.0-481.0] and 441.0 [401.0-495.0] milliseconds respectively $(p=0.49)$.

Table 4 shows the frequency of treatments, stratified by single and polydrug methadone poisoning cases. Among all patients, naloxone was the most commonly used antidote. Four hundred and forty-two patients (45.4\%) received naloxone. Benzodiazepines, the second most frequently administered class of agents, were given to $119(12.3 \%)$ patients. Of those receiving benzodiazepines, 20 patients had seizures, 32 patients had agitation, 46 had withdrawal, and the reason for receiving benzodiazepine in 21 patients was unknown.

Sixty-six percent of patients who experienced coma had acute poisoning, while $47.8 \%$ had acute on chronic poisoning. Of patients who experienced respiratory depression, $49.4 \%$ had acute poisoning, while $66.9 \%$ had acute on chronic poisoning, and 5\% had chronic poisoning. (Table 1 in supplemental data). Three-hundred and eight (69.8\%) patients with coma and $226(51.3 \%)$ patients with respiratory depression received naloxone (Table 2 in supplemental data).

\section{Discussion}

Methadone has been used therapeutically to alleviate pain in patients with chronic disease and to reduce and control withdrawal syndrome in patients who suffer opioid dependency syndrome in methadone maintenance

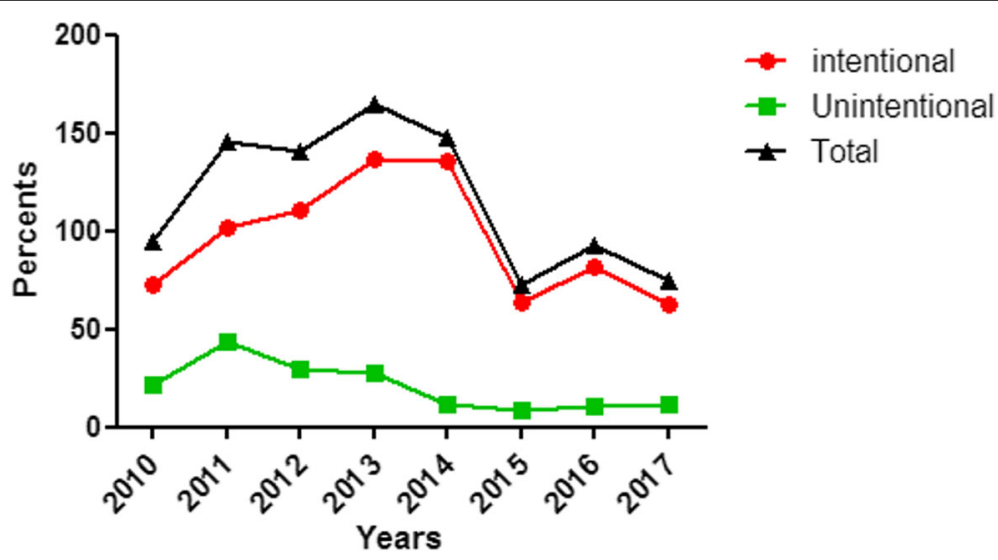

Fig. 1 Distribution of the total number of methadone poisoning cases reported to the ToxlC Registry 2010-2017 


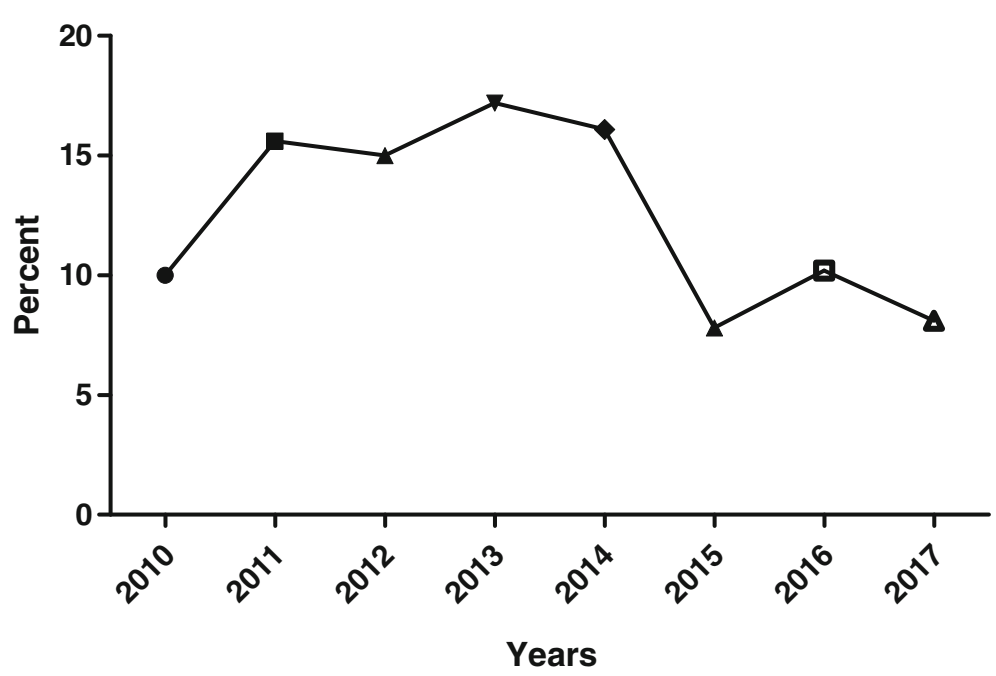

Fig. 2 The percent of all methadone cases/total cases to the ToxIC Registry by year. Frequency distribution of methadone poisoning cases in 2015 had a significant difference with years of 2011, 2012, 2013, $2014(p<0.001)$. Frequency distribution of methadone poisoning cases in 2017 had a significant difference with years of 2011, 2012, 2013, $2014(p<0.001)$. Frequency distribution of methadone poisoning cases in the 2010 as well as 2016 had a significant difference with years of 2011, 2012, 2013, $2014(p<0.001)$.

treatment (MMT) clinics [11]. It has a high potential for abuse and may be used illicitly by opioid-dependent patients [11].

Methadone is well known for its long duration of action and potential for fatality in overdose. This places significant health care and economic burdens on society, especially where death occurs. Mortality costs attributed to methadone accounted for approximately 6.5 million dollars in 2009 in the US [12]. Other studies showed that patients who receive methadone to alleviate chronic pain in pain clinics are at higher risk of mortality [11]. Patients who have chronic pain tend to be older individuals in poorer health who may be receiving multiple medications and experiencing high levels of depression and anxiety. Methadone may be abused by individuals with opioid misuse disorder, which increases its risks

Table 2 The percent of clinical effects in methadone alone poisoning and co-ingestion

\begin{tabular}{llll}
\hline Variable & Total & Single exposure of methadone $(n=354)$ & $\begin{array}{l}\text { Co exposure of Methadone } \\
\text { with other drugs }(n=619)\end{array}$ \\
\hline Coma/CNS & $472(48.6 \%)$ & $354(100 \%)$ & $118(19.1 \%)$ \\
Agitation & $69(7.1 \%)$ & $39(11.1 \%)$ & $30(4.84 \%)$ \\
Seizures & $21(2.2 \%)$ & $13(3.67 \%)$ & $8(1.29 \%)$ \\
Weakness & $6(0.6 \%)$ & $2(0.56 \%)$ & $4(0.64 \%)$ \\
pH $<7$ & $57(5.8 \%)$ & $43(12 / 0 \%)$ & $14(2.26 \%)$ \\
Bradycardia & $41(4.2 \%)$ & $26(7.28 \%)$ & $15(2.42 \%)$ \\
Hypertension & $34(3.5 \%)$ & $24(6.72 \%)$ & $10(16.1 \%)$ \\
Hypotension & $38(3.9 \%)$ & $28(7.91 \%)$ & $10(16.1 \%)$ \\
Tachycardia & $22(2.3 \%)$ & $13(3.67 \%)$ & $9(1.45 \%)$ \\
QTC> 500 milliseconds & $24(2.9 \%)$ & $70(1.64 \%)$ & $4(0.64 \%)$ \\
Acute Kidney injury & $92(9.5 \%)$ & $35(9.88 \%)$ & $22(3.55 \%)$ \\
Rhabdomyolysis & $43(4.4 \%)$ & $44(12.4 \%)$ & $8(1.29 \%)$ \\
Aspiration pneumonitis & $53(5.4 \%)$ & $251(70.9 \%)$ & $9(1.45 \%)$ \\
Respiratory depression & $327(33.6 \%)$ & $28(7.91 \%)$ & $76(12.3 \%)$ \\
Hepatotoxicity (AST > 1000) & $36(3.7 \%)$ & & $8(1.29 \%)$
\end{tabular}

Values are frequency and percentage

The percentages in the methadone only and methadone plus coingestants are calculated in each group

Abbreviations: AST aspartate aminotransferase, CNS central nervous system 
Table 3 Comparison of methadone doses and effect rates in patients with single or co-ingestant exposure of methadone

\begin{tabular}{|c|c|c|c|}
\hline Complications & & $\begin{array}{l}\text { Dose of methadone in } \\
\text { methadone alone (mg) }\end{array}$ & $\begin{array}{l}\text { Dose of methadone in } \\
\text { methadone plus other drugs }(\mathrm{mg})\end{array}$ \\
\hline \multirow[t]{2}{*}{ Coma/Central nervous system (CNS) depression } & Yes & $96.2[56.8-125.0]$ & $97.2[72.3-136.0]$ \\
\hline & No & $65.9[38.6-84.1]$ & $124.3[100.1-168.7]$ \\
\hline \multirow[t]{3}{*}{ Agitation } & Yes & $132.5[98.3-140.7]$ & $119.3[108.9-127.1]$ \\
\hline & No & $125.0[96.2-156.4]$ & $37.5[29.8-65.3]$ \\
\hline & No & $66.6[54.8-89.2]$ & $121.3[95.6-163.8]$ \\
\hline \multirow[t]{2}{*}{ Seizures } & Yes & $138.2[96.5-165.1]$ & $136.9[103.6-172.3]$ \\
\hline & No & $145.2[100.2-189.0]$ & $120.1[89.6-160.3]$ \\
\hline \multirow[t]{2}{*}{ Weakness } & Yes & $43.7[35.6-57.6]$ & $43.6[32.1-68.9]$ \\
\hline & No & $14.2[9.6-25.6]$ & 119.6 [100.0-156.3] \\
\hline \multirow[t]{2}{*}{$\mathrm{pH}<7$} & Yes & $40.2[24.3-50.8]$ & $45 \pm 24.2$ \\
\hline & No & $69.8[57.3-99.2]$ & $124.3[100.6-154.9]$ \\
\hline \multirow[t]{2}{*}{ Bradycardia } & Yes & $42.3[36.8-60.2]$ & $64.5[49.6-87.0]$ \\
\hline & No & $38.6[30.1-45.7]$ & $119.9[96.3-157.6]$ \\
\hline \multirow[t]{2}{*}{ Hypertension } & Yes & $40.2[32.3-50.9]$ & 126.3 [100.5-160.0] \\
\hline & No & $39.6[28.9-61.2]$ & 120.3 [95.6-156.8] \\
\hline \multirow[t]{2}{*}{ Hypotension } & Yes & $32.0[25.3-41.9]$ & $26.3[14.6-38.9]$ \\
\hline & No & $40.9[32.9-53.6]$ & 126.5 [105.3-153.6] \\
\hline \multirow[t]{2}{*}{ Tachycardia } & Yes & $74.9[62.3-90.4]$ & $147.1[125.3-175.1]$ \\
\hline & No & 36.0 [28.9-51.4] & 123.6 [98.0-168.6] \\
\hline \multirow[t]{2}{*}{ QTc $>500$ milliseconds } & Yes & $74.2[52.8-88.6]$ & $32.1[29.6-36.5]$ \\
\hline & No & 34.5 [28.6-58.9] & 128.7 [106.5-150.6] \\
\hline \multirow[t]{2}{*}{ Acute Kidney injury } & Yes & $42.5[14.8-65.3]$ & $16.8[9.8-26.1]$ \\
\hline & No & $117.3[84.0-140.4]$ & 102.3 [86.7-123.9] \\
\hline \multirow[t]{2}{*}{ Rhabdomyolysis } & Yes & $37.5[29.7-50.0]$ & $42.3[19.0-57.8]$ \\
\hline & No & $43.8[34.6-59.9]$ & 124.3 [97.8-150.1] \\
\hline \multirow[t]{2}{*}{ Aspiration pneumonitis } & Yes & $24.6[16.7-36.8]$ & $37.8[26.3-49.0]$ \\
\hline & No & $28.6[14.6-34.5]$ & $124.8[100.1-148.6]$ \\
\hline \multirow[t]{2}{*}{ Respiratory depression } & Yes & $80.3[60.3-100.2]$ & $46.6[34.8-67.2]$ \\
\hline & No & 128.7 [100.2-168.7] & $108.9[85.3-125.6]$ \\
\hline \multirow[t]{2}{*}{ Hepatotoxicity (AST > 1000) } & Yes & $45.2[25.6-59.9]$ & $43.2[29.7-60.0]$ \\
\hline & No & $62.4[48.7-81.0]$ & 122.3 [99.3-145.6] \\
\hline
\end{tabular}

Dose values are mean \pm Standard deviation

*: Mann-Whitney test

$\mathrm{z}=$ test statistics Mann-Whitney

[11]. Our study demonstrated that rates of methadone toxicity in the US, as reflected in the ToxIC database, appeared to increase until 2013-2014, after which there was a decline. Since the ToxIC database is a reflection of cases for which medical toxicology consultation was required, it is likely that more trivial cases are not included. Thus, these data should be interpreted as reflecting significant poisonings.

Another study with different study period has shown that hospital discharge frequency for methadone poisoning rose dramatically through 1997-2007, and then significantly declined through 2007-2014 [13]. This discrepancy may be due to the different study periods and study populations. In that study, the authors analyzed national trends in inpatient and emergency department discharges for opioid abuse, dependence, and poisoning, but in this study, we analyzed just inpatient methadone poisoning cases. In 2005, the Researched Abuse, Diversion and Addiction-Related Surveillance (RADARS) System reported that there was a correlation between the increasing trend in methadone prescriptions and the degree of diversion and abuse, with no meaningful difference in the number of people on methadone maintenance therapy [14]. More recently, the number 
Table 4 Comparison of administered treatments in patients with single and co-ingestant exposures to methadone

\begin{tabular}{lllll}
\hline Variable & & Total & Single exposure of methadone $(n=354)$ & $\begin{array}{l}\text { Co exposure of Methadone } \\
\text { with other drugs }(n=619)\end{array}$ \\
\hline Naloxone & Yes & $442(45.4 \%)$ & $125(35.3 \%)$ & $317(51.2 \%)$ \\
N-acetylcysteine & No & $531(54.6 \%)$ & $232(65.5 \%)$ & $299(48.3 \%)$ \\
Yes & $40(4.2 \%)$ & $27(7.6 \%)$ & $13(2.1 \%)$ \\
Flumazenil & No & $933(95.8 \%)$ & $330(93.2 \%)$ & $603(97.4 \%)$ \\
Sodium bicarbonate & Yes & $22(2.3 \%)$ & $9(2.5 \%)$ & $13(2.1 \%)$ \\
& No & $951(97.7 \%)$ & $348(98.3 \%)$ & $603(97.4 \%)$ \\
Vasopressors & Yes & $21(2.2 \%)$ & $13(2.77 \%)$ & $8(1.29 \%)$ \\
No & $952(97.8 \%)$ & $344(97.2 \%)$ & $608(98.2 \%)$ \\
Anticonvulsants & Yes & $34(3.5 \%)$ & $26(7.34 \%)$ & $8(1.29 \%)$ \\
Antipsychotics & No & $939(96.5 \%)$ & $331(93.5 \%)$ & $608(98.2 \%)$ \\
Yes & $13(1.4 \%)$ & $8(2.3 \%)$ & $5(0.81 \%)$ \\
Benzodiazepine & No & $960(98.6 \%)$ & $349(98.6 \%)$ & $611(98.7 \%)$ \\
Ypes & $25(2.6 \%)$ & $10(2.8 \%)$ & $15(2.42 \%)$ \\
& No & $948(97.4 \%)$ & $347(98.2 \%)$ & $601(97.1 \%)$
\end{tabular}

prescriptions for all opioids has decreased, associated with awareness by practitioners of the dangers of opioids, and national, state, and local measures for reducing the prescribing of opioids [13, 15-17].

The US Centers for Disease Control and Prevention reported that prescriptions for opioids peaked in 2012, with greater than 255 million filled (81.3 prescriptions for every 100 persons). The total national opioid prescription frequency then decreased between 2012 and 2017 , with the lowest rate in the last ten years in 2017, at 58.7 prescriptions for every 100 persons. However, this still represents more than 191 million opioid prescriptions filled [18]. This is consistent with our data. We showed a peak in methadone poisoning in 2013 and 2014, and after that, there was a decline in the number of methadone poisoning cases.

In our study, the mortality rate due to methadone poisoning was $1.4 \%$. However, our patients were admitted to hospitals and thus were alive at presentation. It is possible, however, that the rate of death from methadone poisoning in cases that do not reach a hospital is much higher [19].

Methadone abuse is an important ongoing epidemic, and the 2017 data from the National Poisoning Data System illustratively contains 1054 single methadone poisonings, 456 intentional methadone overdoses, and 56 deaths associated with methadone [20]. Similarly, in a study by Dart et al., methadone was the leading opioid as a cause of death in the NPDS, with 178 cases in 2012 [4].
Coma and respiratory depression were the most common signs of severe methadone toxicity in our study. In a cohort of prescription opioid overdose patients, methadone was the second most commonly prescribed opioid after oxycodone. They showed that the risk factors for severe respiratory depression in patients with prescription opioid overdose include drug misuse (pertinent for methadone), increased age, and the specific opioid medication involved. In that study, methadone had a much higher risk of severe respiratory depression [21]. Other studies revealed that a history of a substance use disorder was closely associated with the development of opioid-induced respiratory depression, with an odds ratio of 12.7 [22].

Patients experiencing these complications ingested a mean of $104 \mathrm{mg}$, which is a lower average dose than our entire cohort. This is likely because non-opioid-tolerant patients are the most vulnerable to adverse effects of opioids, even at lower doses, and there was an overrepresentation of acute ingestions in the group with coma and respiratory depression. Almost 3\% of patients had QTc prolongation, a known, yet uncommon, adverse effect of methadone [1]. It should be noted that the ToxIC Registry does not record minor prolongations of the QT interval. The criterion for QTc prolongation in our database is for it to be over 500 milliseconds. Thus, the actual number of cases that had less consequential QT prolongation was undoubtedly higher. However, complications such as torsade de pointes are 
unlikely at these lower QTc intervals. Nine and a half percent of our patients had acute kidney injury (AKI). Methadone-induced AKI, which may be a consequence of rhabdomyolysis, has been previously reported [23].

Interestingly, we found that $2 \%$ of patients experienced seizures. Most of these patients ingested a high dose of methadone. Methadone-induced seizure has been previously reported [24]. Few studies have evaluated the convulsive effects of methadone and the mechanism behind it. Animal studies showed that acute administration of methadone could substantially reduce the seizure threshold. NMDA and $\mu$-opioid receptors may be involved in methadone's convulsive activity in the acute methadone overdose [25].

In our study, it was found that just half of the patients with respiratory depression received naloxone. Similarly, Aghabiklooei et al. evaluated 322 serious pure methadone-poisoned patients. In their study, naloxone was administered for the treatment of respiratory depression to $40 \%$ of cases in the emergency department or during hospitalization [26]. As with any opioid poisoning, patients with respiratory depression or hypoxia require either naloxone administration or mechanical respiratory support [27].

\section{Limitations}

The number of centers in the ToxIC Registry has changed over time. This is because the quality control procedures in ToxIC have caused poorly performing centers to be dropped, while new centers have joined the Consortium. The total number of cases reported each year has not varied widely, suggesting that the time trends we observed were not due to changes in the total number of cases reported to the ToxIC Registry. Further, as reviewed above, our time trends of serious methadone poisoning cases comport with those seen for all methadone poisonings in other national studies.

Secondly, we have reported the rates of consultations to medical toxicology services and not actual poisoning rates. Thus, our report likely represents the frequency of more serious cases of methadone toxicity. Because the treatment of methadone poisoning has not changed substantially over the study period, it is unlikely that the rate of consultation for serious cases could explain the decline starting in 2015. This suggests that professional and national efforts to curtail opioid toxicity have resulted in a trend of decreasing numbers of cases of serious methadone intoxication.

Understanding the pattern of opioid use in the US is necessary before effective measures to reduce morbidity and mortality from opioid use can be instituted. The opioid epidemic continued to increase after 2017; however, we could not present that data after 2018. Despite this, the time trends represent a component of the overall dynamic of "waves of the opioid epidemic." By 2018, the "third wave" created by fentanyl and its analogs was underway, with methadone playing a lesser role.

\section{Conclusion}

Our data demonstrate that rates of methadone poisoning increased in 2010-2014, followed by a decline in 2015-17.

\section{Supplementary information}

Supplementary information accompanies this paper at https://doi.org/10 1186/s40360-020-00435-0.

Additional file 1: Table 1. Distribution of clinical effects based on the chronicity of use in methadone poisoning patients Table 2. Frequency of Receiving naloxone based on clinical effects

\section{Acknowledgements}

Not applicable.

Authors' contributions

$\mathrm{OM}, \mathrm{CH}, \mathrm{AA}, \mathrm{JB}$ contributed to conception, design, and preparation of the manuscript. $\mathrm{OM}$ and $\mathrm{JB}$ conducted the data collection and contributed to acquisition, and interpretation. $\mathrm{OM}, \mathrm{CH}, \mathrm{AA}, \mathrm{JB}$ made substantial contributions in drafting the manuscript, and revising it critically for important intellectual content. All authors have read and approved the final version of manuscript.

\section{Funding}

No funding was obtained for this study.

\section{Availability of data and materials}

The datasets used and/or analysed during the current study available from the corresponding author on reasonable request. All data used for this study was obtained from the Toxicology Investigators Consortium (https://www. ToxICRegistry.org) with permission by ToxIC after an application by the first author, who is currently in possession of the data set used in this analysis. Because the Western Institutional Review Board (WIRB) has concluded that the data collection in ToxIC does not meet the definition of Human Subjects Research and was approved by ToxIC no further ethics committee permission was deemed necessary.

\section{Ethics approval and consent to participate}

This study complies with national guidelines. It was done on a subset of data from the Toxicology Investigators Consortium's (ToxIC's) database. The data collection for ToxIC was reviewed by the Western Institutional Review Board (WIRB) and because no personal health information was collected and there was patient intervention it was judged not to be human subjects research. All institutions contributing data did so after review and acceptance by their Institutional Review Boards.

\section{Consent for publication}

Not Applicable.

\section{Competing interests}

The corresponding author of this article is one of the associate editors of the journal of BMC pharmacology and toxicology. Other co-authors have no competing interests.

\section{Author details}

${ }^{1}$ Rocky Mountain Poison and Drug Center, Denver Health and Hospital Authority, 1391 Speer Blvd, 777 Bannock St. MC 0180, Denver, CO 80204, USA. ${ }^{2}$ Medical Toxicology and Drug Abuse Research Center (MTDRC), Birjand University of of Medical Sciences, Birjand, Iran. ${ }^{3}$ Department of Emergency 
Medicine and Medical Toxicology, University of Colorado Anschutz Medical Campus, University Hospital, Aurora, CO, USA. ${ }^{4}$ Cardiovascular Diseases Research Center Birjand University of Medical Sciences, Birjand, Iran. ${ }^{5}$ School of medicine, University of Colorado, Aurora, CO, USA.

Received: 12 December 2019 Accepted: 16 July 2020

Published online: 22 July 2020

\section{References}

1. Alinejad S, Kazemi T, Zamani N, Hoffman RS, Mehrpour O. A systematic review of the cardiotoxicity of methadone. Excli J. 2015;14:577.

2. Alinejad S, Zamani N, Abdollahi M, Mehrpour O. A narrative review of acute adult poisoningin Iran. Iran J Med Sci. 2017;42(4):327.

3. Graham NA, Merlo LJ, Goldberger BA, Gold MS. Methadone- and heroinrelated deaths in Florida. Am J Drug Alcohol Abuse. 2008;34(3):347-53.

4. Dart RC, Bronstein AC, Spyker DA, Cantilena LR, Seifert SA, Heard SE, et al. Poisoning in the United States: 2012 emergency medicine report of the National Poison Data System. Ann Emerg Med. 2015;65(4):416-22.

5. Akhgari M, Amini-Shirazi N, Iravani FS. Forensic toxicology perspectives of methadone-associated deaths in Tehran, Iran, a 7-year overview. Basic Clin Pharmacol Toxicol. 2018;122(4):436-41.

6. Thanavaro KL, Thanavaro JL. Methadone-induced torsades de pointes: a twist of fate. Heart Lung. 2011;40(5):448-53.

7. Alderks CE. Trends in the Use of Methadone, Buprenorphine, and ExtendedRelease Naltrexone at Substance Abuse Treatment Facilities: 2003-2015 (Update). In: The CBHSQ Report. Rockville (MD): Substance Abuse and Mental Health Services Administration (US); 2013. p. 1-8.

8. Wax PM, Kleinschmidt KC, Brent J. ACMT ToxIC case registry investigators. The toxicology investigators consortium (ToxIC) registry. J Med Toxicol. 2011;7(4):259-65.

9. Monte AA, Calello DP, Gerona RR, Hamad E, Campleman SL, Brent J, Wax P, Carlson RG. ACMT toxicology investigators consortium. Characteristics and treatment of patients with clinical illness due to synthetic cannabinoid inhalation reported by medical toxicologists: a ToxIC database study. J Med Toxicol. 2017:13(2):146-52.

10. Rhyee SH, Farrugia L, Wiegand T, Smith EA, Wax PM, Brent J. Toxicology investigators consortium. The toxicology investigators consortium case registry-the 2013 experience. J Med Toxicol. 2014;10(4):342-59.

11. Modesto-Lowe V, Brooks D, Petry N. Methadone deaths: risk factors in pain and addicted populations. J Gen Intern Med. 2010;25(4):305-9. https://doi. org/10.1007/s11606-009-1225-0 Epub 2010 Jan 20. PMID: 20087676; PMCID: PMC2842557.

12. Inocencio TJ, Carroll NV, Read EJ, Holdford DA. The economic burden of opioid-related poisoning in the United States. Pain Med. 2013;14(10):153447. https://doi.org/10.1111/pme.12183.

13. Tedesco D, Asch SM, Curtin C, Hah J, McDonald KM, Fantini MP Hernandez-Boussard T. Opioid abuse and poisoning: trends in inpatient and emergency department discharges. Health Aff (Millwood). 2017; 36(10):1748-53.

14. Cicero TJ, Inciardi JA. Diversion and abuse of methadone prescribed for pain management. JAMA. 2005;293(3):297-8. https://doi.org/10.1001/jama. 293.3.297.

15. Office of the Press Secretary [Internet]. Washington (DC): WhiteHouse. Press release, Fact sheet: President Obama proposes $\$ 1.1$ billionin new funding to address the prescription opioid abuse and heroin use epidemic; 2016 Feb 2. [cited2017 Jul 19]. Available from: https://obamawhitehouse.archives.gov/ thepress-office/2016/02/02/presidentobama-proposes-11-billionnewfunding-address-prescription. Accessed 24 Feb 2018.

16. Dowell D, Haegerich TM, Chou R. CDC guideline for prescribing opioids for chronic pain-United States, 2016. MMWR Recomm Rep. 2016;65(1):1-49.

17. American Medical Association. Reversing the opioid epidemic. Chicago: AMA. Available from: https://www.ama-assn.org/delivering-care/reversingopioid-epidemic; [cited 2017Jul 19].

18. Center for control disease and prevention (CDC), USS Opioid Prescribing Rate Maps. Available at: https://www.cdc.gov/drugoverdose/maps/rxratemaps.html. Accessed 30 Aug 2019.

19. Ray WA, Chung CP, Murray KT, Cooper WO, Hall K, Stein CM. Out-of-hospital mortality among patients receiving methadone for noncancer pain. JAMA Intern Med. 2015;175(3):420-7.

20. Gummin DD, Mowry JB, Spyker DA, Brooks DE, Osterthaler KM, Banner W. 2017 annual report of the American Association of Poison Control Centers'
National Poison Data System (NPDS): 35th annual report. Clin Toxicol (Phila). 2018 Dec;56(12):1213-415.

21. Fox LM, Hoffman RS, Vlahov D, Manini AF. Risk factors for severe respiratory depression from prescription opioid overdose. Addiction. 2018;113(1):59-66. https://doi.org/10.1111/add.13925 Epub 2017 Sep 6. PMID: 28646524; PMCI D: PMC5725269.

22. Zedler BK, Saunders WB, Joyce AR, Vick CC, Murrelle EL. Validation of a Screening Risk Index for Serious Prescription Opioid-Induced Respiratory Depression or Overdose in a US Commercial Health Plan Claims Database. Pain Med. 2018;19(1):68-78.

23. Alinejad S, Ghaemi K, Abdollahi M, Mehrpour O. Nephrotoxicity of methadone: a systematic review. Springerplus. 2016;5(1):2087. https://doi. org/10.1186/s40064-016-3757-1 eCollection 2016.

24. Bertol E, Bigagli L, D'Errico S, Mari F, Palumbo D, Pascali JP, Vaiano F. Analysis of illicit drugs seized in the province of Florence from 2006 to 2016. Forensic Sci Int. 2018;284:194-203. https://doi.org/10.1016/j.forsciint. 2018.01.010.

25. Kazemi Roodsari S, Bahramnejad E, Rahimi N, Aghaei I, Dehpour AR. Methadone's effects on pentylenetetrazole-induced seizure threshold in mice: NMDA/opioid receptors and nitric oxide signaling. Ann N Y Acad Sci. 2019;1449(1):25-35. https://doi.org/10.1111/nyas.14043.

26. Aghabiklooei A, Edalatparvar M, Zamani N, Mostafazadeh B. Prognostic factors in acute methadone toxicity: a 5-year study. J Toxicol. 2014;2014: 341826

27. Brent J, Burkhart K, Dargan P, Hatten B, Megarbane B, Palmer R, White J, editors. Critical care toxicology: diagnosis and management of the critically poisoned patient: Springer; 2017. Berlin.

\section{Publisher's Note}

Springer Nature remains neutral with regard to jurisdictional claims in published maps and institutional affiliations.

\section{Ready to submit your research? Choose BMC and benefit from:}

- fast, convenient online submission

- thorough peer review by experienced researchers in your field

- rapid publication on acceptance

- support for research data, including large and complex data types

- gold Open Access which fosters wider collaboration and increased citations

- maximum visibility for your research: over $100 \mathrm{M}$ website views per year

At $\mathrm{BMC}$, research is always in progress.

Learn more biomedcentral.com/submissions 